Supplemental material

2

\title{
Evolution of air quality in Santiago: the role of mobility and lessons from the science-policy interface
}

Laura Gallardo ${ }^{1,2^{*}}$, Francisco Barraza ${ }^{1,3}$, Andrés Ceballos ${ }^{1,4}$, Mauricio Galleguillos ${ }^{1,4}$, Nicolás Huneeus $^{1,2}$, Fabrice Lambert ${ }^{1,3}$, Cecilia Ibarra ${ }^{1}$, Marcela Munizaga ${ }^{1,5,6}$, Raúl O’Ryan ${ }^{1,7}$, Mauricio Osses ${ }^{1,8}$, Sebastián Tolvett ${ }^{1,9}$, Anahí Urquiza ${ }^{1,10}$, Karina D. Véliz ${ }^{1,11}$

*Corresponding author: lgallard@u.uchile.cl March 27th 2018

Here we provide information regarding acquisition and handling of air quality data collected in downtown Santiago at station Parque O'Higgins, and shown in Table 4 in the manuscript.

We considered all data on gaseous pollutants available until December 2016 at http://sinca.mma.gob.cl, and downloaded on January $21^{\text {st }} 2018$. The publically available data base contains non-validated data, preliminary validated data and validated data, in Spanish "no validados", "preliminares" and "validados". Non-validated data have not been inspected by officials from the Ministry for the Environment. Preliminary validated data have been scanned by a person. Validated data are those subject to calibration and inspected by a responsible person. To assure consistently long time series of monthly averaged values among the different gaseous species available, we applied the following filtering criteria to all data, i.e., non-validated, preliminary validated and validated data:

- Eliminate negative values if any

- When calculating monthly averages, we considered days with $75 \%$ completeness of the diurnal cycle, i.e., days with at least 6 readings of hourly mixing ratios/concentrations every 8 hours, i.e., between $1-8,9-16,17-24$ local time. Also, only months with $75 \%$ of the data.

- Eliminate data where the central value of the pollutant is 5 times higher than its neighbors

- Eliminate data whose concentrations are less than twice the nominal detection limit of the instrument.

- In the case of nitrogen oxides, we imposed $\mathrm{NO}_{\mathrm{x}} \geq \mathrm{NO}+\mathrm{NO}_{2}$ 


\begin{tabular}{|l|c|l|l|}
\hline Species (unit) & Detection Limit & Instrument & Measurement principle \\
\hline $\mathrm{SO}_{2}(\mathrm{ppb})$ & 0.5 & Thermo $43 \mathrm{i}$ & Fluorescence \\
\hline $\mathrm{CO}(\mathrm{ppm})$ & 0.04 & Thermo $48 \mathrm{i}$ & IR Absorption \\
\hline $\mathrm{NO}(\mathrm{ppt})$ & 50 & Thermo $42 \mathrm{i}$ & Chemiluminiscence \\
\hline $\mathrm{NO}_{2}(\mathrm{ppt})$ & 50 & Thermo $42 \mathrm{i}$ & Chemiluminiscence \\
\hline $\mathrm{NO}_{\mathrm{x}}(\mathrm{ppt})$ & 50 & Thermo $42 \mathrm{i}$ & Chemiluminiscence \\
\hline $\mathrm{O}_{3}(\mathrm{ppb})$ & 1 & Thermo 49i & UV Absorption \\
\hline
\end{tabular}

31

32 Particulate matter data were directly provided by Officials from the Ministry for the Environment

33 (RMartinez.rm@mma.gob.cl) on November 2017. In this case, we only imposed positivity and

34 PM25/PM10 $\leq 1$. Copies of these datasets are available at: http://www.cr2.cl/recursos-y-publicaciones/AQ-

35 Santiago/. Historic data previous to 1997 are also shown in this repository.

36

37 